\title{
Saponin synthesis and cotton growth is antagonistically regulated by solar UV-B radiation
}

\author{
DEHARIYA Priti ${ }^{1}$, KATARIA Sunita2 ${ }^{2}$, GURUPRASAD Kadur Narayan ${ }^{3}$ and PANDEY Govind Prakash ${ }^{1}$
}

\begin{abstract}
Background: Earlier we have reported that the exclusion of solar UV-B increased the growth and yield of cotton plants as compared with ambient UV-B. The UV-B radiation effects on the saponins and the impact of ambient and reduced UV-B on the accumulation of saponins has not been investigated yet. Thus a field experiment was conducted to study the influence of solar UV-B on the growth response and saponin synthesis in cotton (Gossypium hirsutum) var. Vikram plants by the exclusion of UV-B. The cotton plants were grown in specially designed iron chambers, wrapped with filters that excluded UV-B $(<315 \mathrm{~nm})$, or transmitted ambient UV-B.

Results: Exclusion of ambient UV-B enhanced the growth of cotton plants in terms of plant height and leaf area. Greater plant height in UV-B excluded plants was due to elongated internode and more number of nodes. Enhancement in growth was accompanied by a decrease in the accumulation of saponins, which was quantified by the spectrophotometric, TLC and HPLC methods. Solvent extraction of saponins from the internodes and leaves were used for the bioassay of Amaranthus hypocotyl growth and expansion of cucumber cotyledons. Extracts obtained from the UV-B excluded plants (leaves and internodes) promoted the growth to a larger extent as compared with the extracts obtained from ambient grown plants.
\end{abstract}

Conclusions: The result indicates that solar UV-B may possibly suppress the plant growth by regulating the synthesis of natural growth inhibitor's like saponin.

Keywords: Bioassay, Cotton, Growth, Inhibitor, Saponin, UV radiation

\section{Introduction}

Ultraviolet (UV)-B radiation $(280-315 \mathrm{~nm})$ is a natural component of sunlight. The amount of UV-B radiation reaching the Earth's surface has increased over the last decade due to ozone depletion (Caldwell et al. 2003; McKenzie et al. 2011). Enhanced UV-B radiation can alter plant photosynthesis (Reddy et al. 2004), water metabolism (Fuhrer and Booker 2003) and the carbon partitioning from growth pools to secondary metabolic pathways (Bassman 2004).

The level of ambient UV-B radiation in sunlight varies with reference to latitude. Crop plants grown under tropical conditions receive approximately 50\% higher dose of UV-B in the natural solar radiation compared

\footnotetext{
* Correspondence: sunita_kataria@yahoo.com

${ }^{2}$ School of Biochemistry, Devi Ahilya University, Khandwa Road, Indore 452

001, India

Full list of author information is available at the end of the article
}

with temperate regions due to small solar zenith angle and thin stratospheric ozone layer in tropics (Madronich et al. 1995; McKenzie et al. 2011). The impact of UV-B on plants is studied either by supplementation of UV-B with artificial light screen or by excluding the UV-B component from the solar spectrum using appropriate filters. Exclusion studies provide exact data on the impact of ambient UV-B on the plants. Enhancement of growth after the exclusion of UV-B component from the solar spectrum has been observed in plants like Amaranthus (Kataria and Guruprasad 2014), wheat (Kataria and Guruprasad 2012a, b), Cyamopsis and Vigna (Amudha et al. 2005), cucumber (Krizek and Mirecki 2004), cotton (Dehariya et al. 2012; Kataria et al. 2013) and soybean (Guruprasad et al. 2007; Baroniya et al. 2014; Zhang et al. 2014). Thus solar UV-B exclusion studies confirmed that ambient UV-B caused reduction in the plant height, internodal length and leaf area. 
Saponin-triterpenoid glycosides are one of the most interesting groups of secondary metabolites. The saponins are a group of plant glycosides in which hydrophilic sugars are attached to alipophilic steroid or triterpenoid moiety. The growth inhibitory effects of triterpenoids saponins have been shown earlier using alfalfa seeds (Ohara and Ohira 2003). Three triterpenoids (betulin, betulinic acid and oleanolic acid) inhibited radical and hypocotyl growth in alfalfa seeds (Ohara and Ohira 2003). The inhibitory effects of triterpenoid saponins are thought to be attributed not to the property of their aglycons but to that of the whole of their molecules (Saha et al. 2010). Saponins are widely distributed in plants and involved in various biological activities such as antimicrobial, antitermitic, molluscicidol and anti-human immunodeficiency virus-1 (HIV-1) protease (Crombie et al. 1987; Marston and Hostettman 1987; Ohmura et al. 1997; Yang et al. 1999).

Furthermore, a few studies indicated a promoting effect of higher light intensities on saponin concentrations in plants (Mathur et al. 2000; Maulidiani et al. 2012). Besides flavonoids, the accumulation of other secondary compounds in response to UV-B exposure, probably act as UV-protectants (Zhang et al. 2009; Inostroza-Blancheteau et al. 2014). It was proposed that the saponins were increased by UV-B radiation (Afreen et al. 2005). Ambient UV-B also caused 70\% increase in the saponins content of leaf extract of Coleus aromaticus as compared with the control (Kumari and Prasad 2014). However, findings are limited and even contradictory (Szakiel et al. 2011). Moreover, the impact of ambient and reduced UV-B on the accumulation of saponins has not yet been investigated. The objective of the present study was to extract the saponin and to analyze by bioassays as well as by TLC and HPLC from the cotton plants grown in the presence or in the absence of UV-B component of the solar spectrum. Cotton (Gossypium hirsutum), an important cash crop of India, is sensitive to UV-B radiation (Kakani et al. 2003). We present the results of the experiments in this paper that indicate the involvement of saponins as growth inhibitors and that UV-B components of the solar spectrum alter the saponin content in the plants.

\section{Material and Methods}

\section{Plant material and growth conditions}

Seeds of cotton (G. hirsutum var. Vikram) were collected from Cotton Improvement Project, Agriculture College, Indore and treated with recommended fungicides viz. Bevistin and Diathane $M$ at $2{\mathrm{~g} \cdot \mathrm{kg}^{-1}}$ seeds. Field experiments under natural sunlight were conducted in the Botanical garden of School of Life Sciences, Indore $\left(22.4^{\circ} \mathrm{N}\right)$, India. The experiments were carried out during February to May 2013. Cotton seeds were sown inside iron cages
$(120 \mathrm{~cm} \mathrm{~L} \times 90 \mathrm{~cm} \mathrm{~W} \times 150 \mathrm{~cm} \mathrm{H})$ in $90 \mathrm{~cm}$ row length and $30 \mathrm{~cm}$ space between the rows. Plants were irrigated and fertilized (NPK) at regular intervals to avoid nutritional deficiencies. The iron cages were wrapped with UV cut-off filters (Garware polyester Ltd., Mumbai) that selectively cut off UV-B $(<315 \mathrm{~nm})$ radiation. Filter control plants were grown in the cages covered with polythene film that transmits all the ambient solar radiation. The transmissions of the filters were measured by Shimadzu (UV-1601) as presented in Fig. 1. The filters were replaced every 15 days as they became brittle because of solarization. The bottom sides of all the cages $(0.35 \mathrm{~m}$ above ground) were left uncovered to allow normal ventilation. The frames received full solar radiation for most of the day without any shading. Temperatures both inside and outside of each enclosure were monitored daily using $\mathrm{max} / \mathrm{min}$ thermometers. Irrigation was given when required for optimal growth of the crop. Soil of the study site was black cotton soil (sand 10\%, silt $60 \%$ and clay $30 \%$ ). During the experimental period, average temperature ranged from $25{ }^{\circ} \mathrm{C}$ to $37{ }^{\circ} \mathrm{C}$ and relative humidity ranged from $55 \%$ to $75 \%$.

\section{Radiation measurement}

Solar irradiance with and without UV-B was measured using a radiometer (Solar light Co. Inc. (PMA 2 100), Glenside, PA, USA) between 11:30 am and 12:00 pm during experimental period. The photosynthetic active radiation (PAR) during experimental period at midday was $1450 \mu \mathrm{mol} \cdot \mathrm{m}^{-2} \cdot \mathrm{s}^{-1}$; the loss in light intensity at midday by -UV-B filters was $12.5 \%\left(1270 \mu \mathrm{mol} \cdot \mathrm{m}^{-2} \cdot \mathrm{s}^{-1}\right)$ and $4.2 \%\left(1390 \mu \mathrm{mol} \cdot \mathrm{m}^{-2} \cdot \mathrm{s}^{-1}\right)$ under polythene filter transmissible to UV (Filter Control).

\section{Growth analysis}

Plant height, number of nodes, average internodal length and area of leaf $\left(9^{\text {th }}\right)$ were taken at 70 days after emergence (DAE) of seedlings. Area of leaf was taken by pressing the blotted dry leaf on the graph paper and tracing the exact outline. The mean of five leaves was taken as the average value. The calibration curve was prepared by weighing $0-1000 \mathrm{~mm}^{2}$ area of graph paper.

\section{Successive extraction method}

Cotton internodes/leaves (filter control and -UV-B) of $50 \mathrm{~g}$ were dipped in $400 \mathrm{~mL}$ of $50 \%$ methanol for $72 \mathrm{~h}$. The extract was then filtered through Bucchnner funnel (110 $\mathrm{mm}$ diameter) lined with Whatmann \pm 4 filter paper. Methanolic fraction $(50 \mathrm{~mL})$ was used for successive extraction procedure (Tiwari et al. 2011). Further extraction was carried out as given in Fig. 2. 


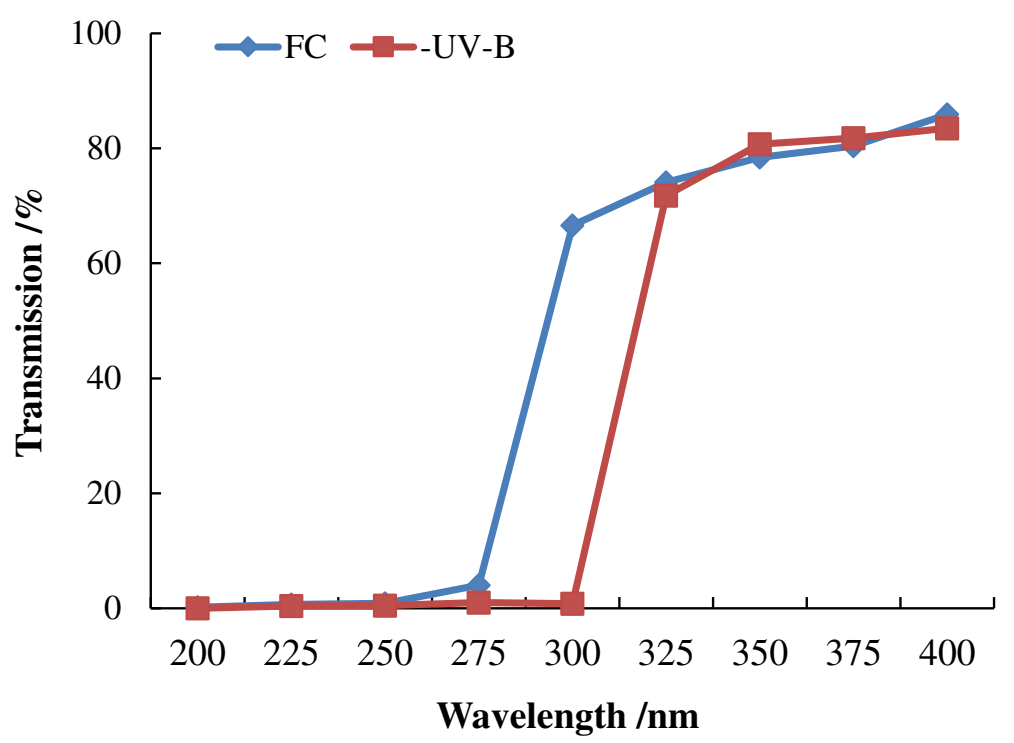

Fig. 1 Transmission spectra of UV-B cut-off filters used for UV-B exclusion and polythene filters used for filter control (FC) for raising cotton plants var. Vikram under field conditions

Ethyl acetate layer in the final step was evaporated to dryness and dissolved in distilled water and used for the bioassays of longitudinal growth of Amaranthus hypocotyl and of expansion growth bioassay of cucumber cotyledons in darkness as well as in light.

\section{Quantitative estimation of triterpenoids}

The quantification of triterpenoids was determined by the modified method of Kolawole et al. (2006). Ethyl acetate fraction $(2 \mathrm{~mL})$ obtained from cotton leaf and an internodal segment (Control and -UV-B) was treated with $0.5 \mathrm{~g}$ of 2, 4-dinitrophenyl hydrazine dissolve in 100 $\mathrm{mL}$ of $2 \mathrm{~mol} \cdot \mathrm{L}^{-1} \mathrm{HCl}$. The orange coloration obtained due to the presence triterpenoids (saponin) and the absorbance was measured at $452 \mathrm{~nm}$ by a spectrophotometer (Shimadzu UV/Vis 1601). The amount of saponin was calculated as saponin equivalent from the calibration curve of standard saponin (100 to $1000 \mu \mathrm{g} \cdot \mathrm{mL}^{-1}$ ).
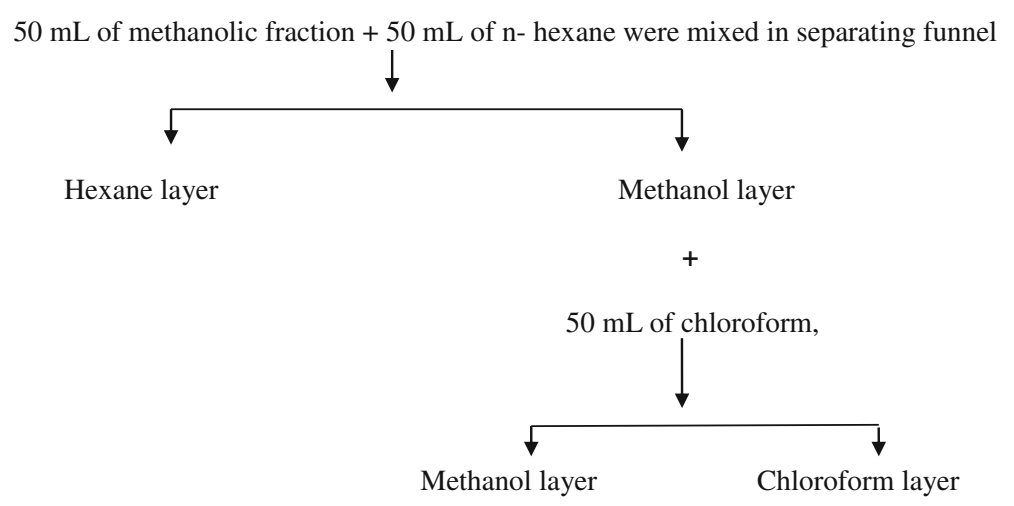

$+50 \mathrm{~mL}$ of Ethyl acetate

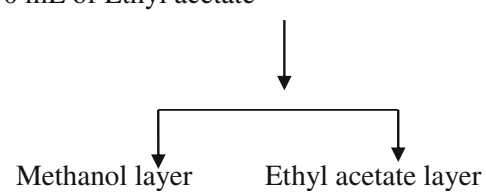

Fig. 2 Successive extraction procedure of saponins from internodes and leaves of cotton plants var. Vikram grown in filter control (FC) and UV-B excluded conditions. 


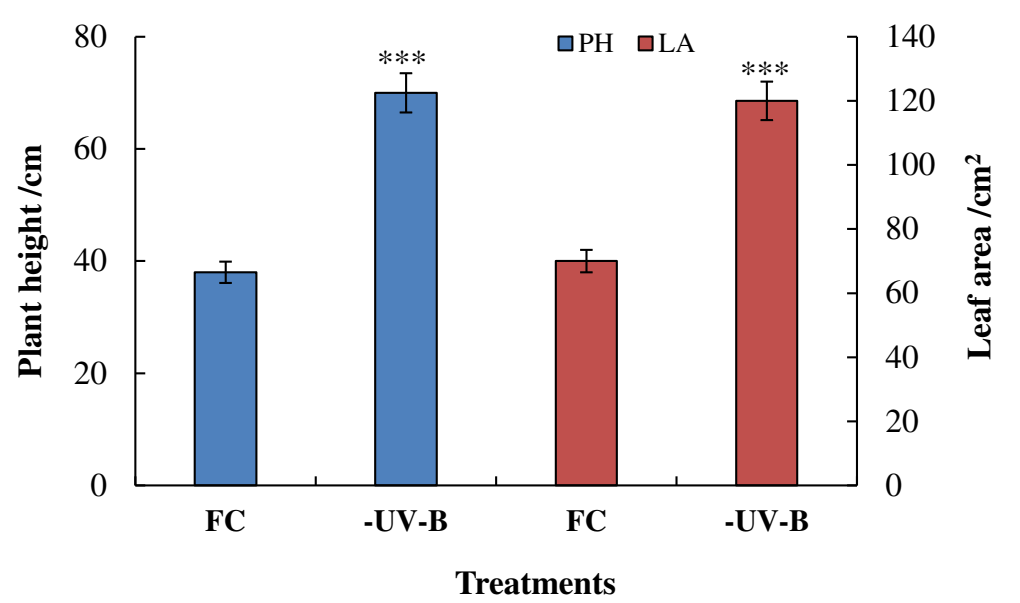

Fig. 3 Effect of exclusion of UV-B on plant height and leaf area of cotton seedlings var. Vikram grown in filter control (FC) and UV-B excluded conditions. The vertical bar indicates \pm SE for mean. Values are significantly different at ${ }^{* * *} P<0.001$ from filter control

\section{TLC analysis of the ethyl acetate fraction}

Thin-layer chromatography of ethyl acetate fraction obtained by successive extraction from filter control and UV-B excluded leaves was carried out on a $10 \times 10 \mathrm{~cm}$ $(0.20 \mathrm{~mm}$ thick) silica gel plate (Merck Kieselgel 60 F254), using chloroform: ethanol: acetic acid (60:40:5 in volume of $\mathrm{CHCl}_{3}, \mathrm{EtOH}$ and $\mathrm{AcOH}$ ) as a developing solvent. Plate was developed up to $7 \mathrm{~cm}$ from the starting line. Plate was sprayed with anisaldehyde- $\mathrm{H}_{2} \mathrm{SO}_{4}$ as a color reagent then heated $\left(100{ }^{\circ} \mathrm{C}\right)$. Spots were observed under visible light (Cristian et al. 2005). After drying the plate, spots of all treatments (saponin Std, Control, -UV-B) at Rf 0.285 and these spots were scratched and dissolved in 50\% methanol and UV spectra was taken at wavelength $200-700 \mathrm{~nm}$ in a UV/Vis spectrophotometer (Shimadzu 1601).

\section{HPLC analysis of the ethyl acetate fraction}

HPLC analysis of the ethyl acetate fraction of cotton leaves were performed with a Shimadzu HPLC system equipped with Phenomenex 'Luna $5 \mu \mathrm{m} \mathrm{C18} 100 \AA$, LC Column $250 \times 4.6 \mathrm{~mm}$ ' column, LC10AT VP pumps, SCL-10AVP system controller, SIL-10AD VP auto injector, SPD-M10 AVP photodiode array detector and the data was processed using VP software.

For this method, the used mobile phase was a mixture of $0.05 \mathrm{~mol} \cdot \mathrm{L}^{-1}$ sodium sulphate buffer $(\mathrm{pH} 2.3)$ and acetonitrile (68.5: 31.5, in volume of sodium sulphate buffer and acetonitrile) at a flow rate of $1 \mathrm{~mL} \cdot \mathrm{min}^{-1}$ and the column temperature was maintained at $30{ }^{\circ} \mathrm{C}$. The detection wavelength was set at $205 \mathrm{~nm}$. The injection volume was $20 \mu \mathrm{L}$ and the chromatography system was equilibrated by the mobile phase. The separation and quantification of the samples were conducted when the same retention time and peak areas of the repetitive injection of the standard solutions were obtained. The total run time was $75 \mathrm{~min}$.

\section{Statistical analysis}

All the data are presented in triplicates $(n=3)$ and the data are expressed as means \pm S.E.M. and were analyzed by the analysis of variance followed by post hoc Newman-Keulis multiple comparison test by using Prism 4 software for Windows, Graf Pad Software, Inc., LaJolla, CA, USA.

\section{Results}

\section{UV exclusion and growth}

Cotton plants grown under UV-B exclusion filters for 70 DAE showed an enhancement in the height of the plant and in the area of leaf (Fig. 3). The enhancement in height was by $68 \%$ and in leaf area by $79 \%$ as compared with the FC. The enhancement in height because of exclusion of UV-B was due to increase in the number of nodes ( $27 \%$ over control) as well as the internodal length (37\% over control) (Table 1).

\section{Saponin content}

The saponin content was estimated in the ethyl acetate fraction of the leaf extracts. Saponin content was higher in the leaves of plants grown under ambient UV-B but

Table 1 Effect of exclusion of UV-B on number of nodes and internodal length of cotton seedlings var. Vikram

\begin{tabular}{lll}
\hline Treatments & No. of nodes & Internodal length/cm \\
\hline FC & $17.6 \pm 1.0$ & $4.03 \pm 0.5$ \\
-UV-B & $22.3 \pm 1.2^{*}(127)$ & $5.52 \pm 0.6^{* * *}(137)$
\end{tabular}

Values are significantly different at ${ }^{*} P<0.05$, ${ }^{* * *} P<0.001$ from filter control (Newman-Keulis Multiple Comparison Test)

The numbers in brackets are percent changes with reference to respective filter controls

(FC Filter control, -UV-B UV-B Exclusion) 


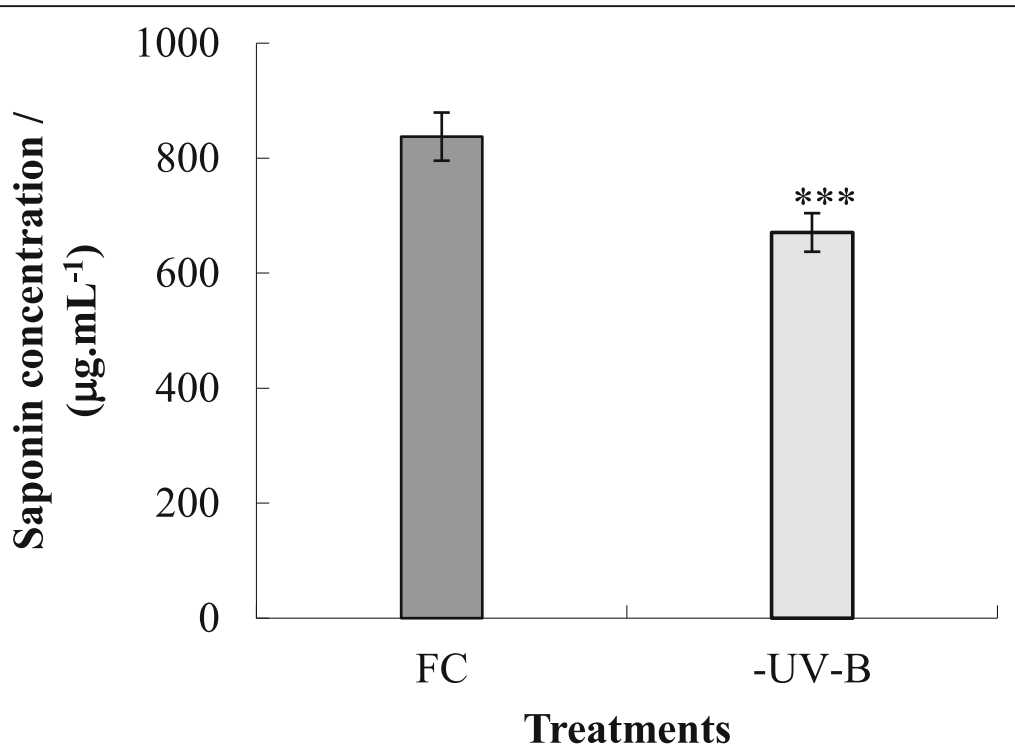

Fig. 4 Saponin content in leaves of cotton var. Vikram grown in filter control (FC) and UV-B excluded conditions. The vertical bar indicates \pm SE for mean. Values are significantly different at ${ }^{* *} P<0.01$ from filter control

lower in the UV-B excluded plants (Fig. 4). Overlaying the UV absorption spectra of standard saponin (Fluka Analytical) over the extracted saponin indicated a significant quantitative difference between the two extracts of filter control and the UV-B excluded plants (Fig. 5).

The HPLC separation of fractions of the leaf extracts of cotton plants also showed a significant quantitative difference between the extracts obtained from filter control plants and the UV-B excluded plants at the Retention time $=3.23$ (Fig. 6, Table 2) compared with similar band of the standard.

\section{Bioassays with standard saponin}

Standard saponin (Fluka Analytical) used in the concentration range of $0-2000 \mu \mathrm{g} \cdot \mathrm{mL}^{-1}$ inhibited the growth of Amaranthus hypocotyl in darkness and in light (Fig. 7a).

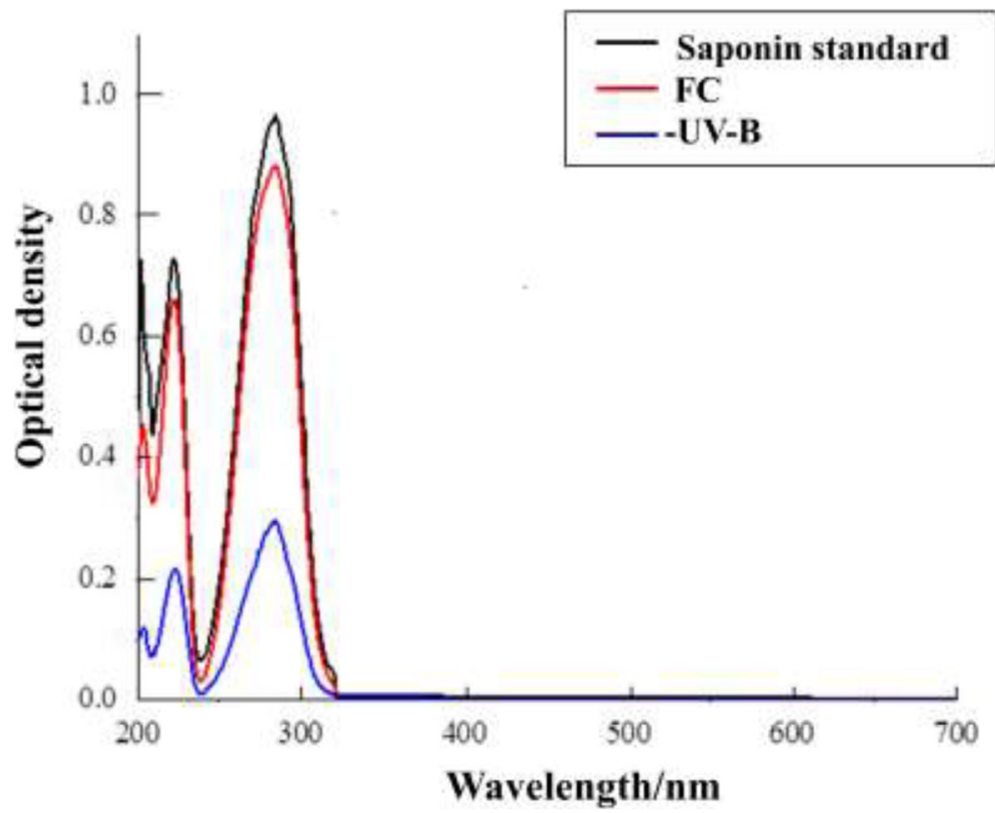

Fig. 5 Overlay UV absorption spectra of saponin standard and the corresponding band in the sample extracted from leaves of cotton var. Vikram plants grown in filter control and UV-B excluded conditions. (Spots were scratched from TLC plate at Rf 0.285 and dissolved in 50\% methanol) 

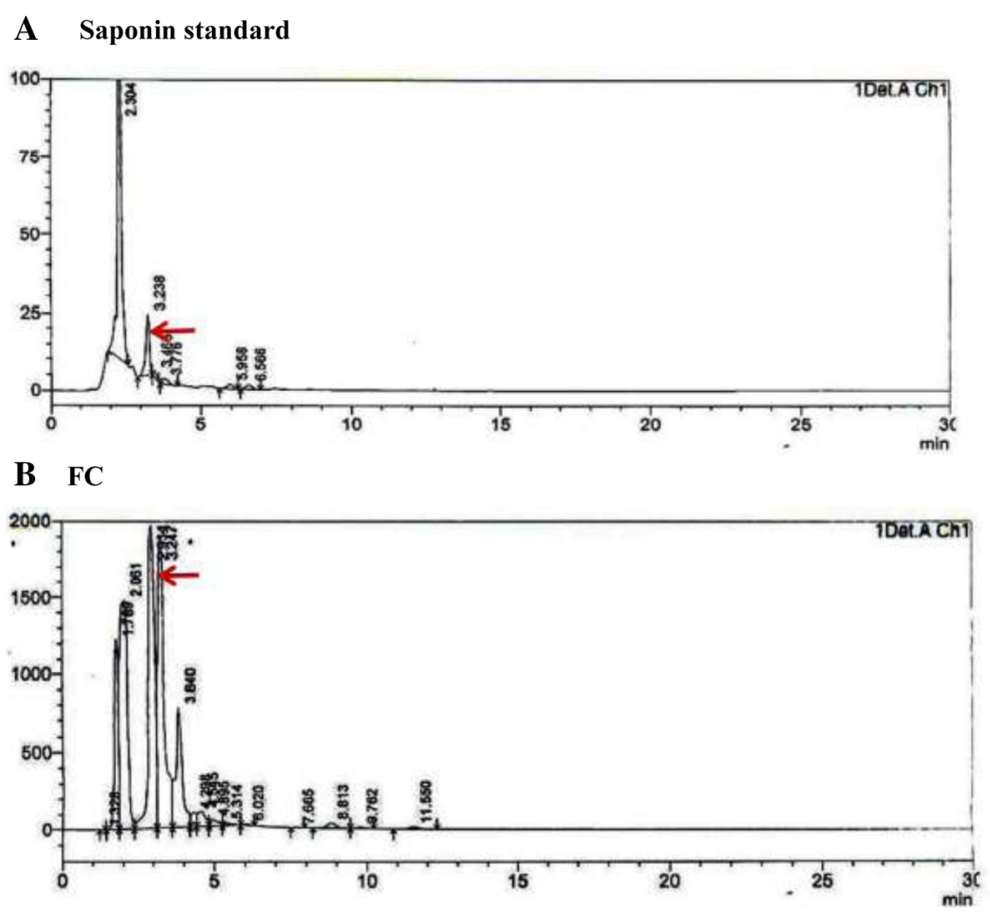

C $\quad$-UV-B

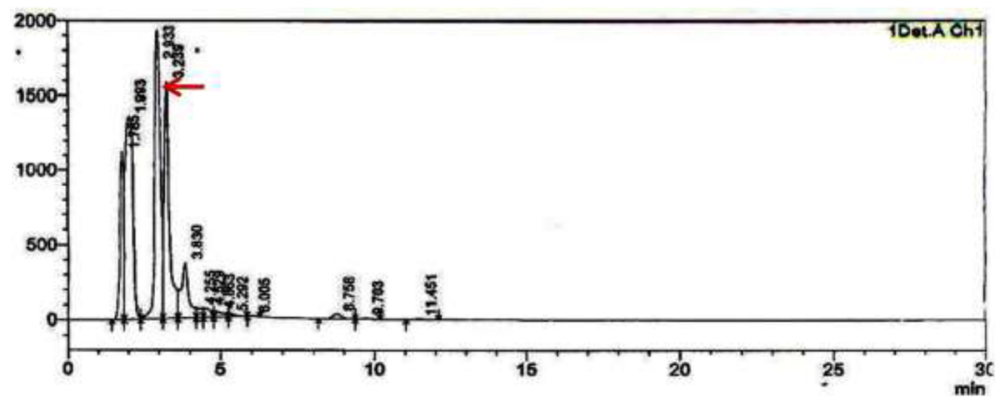

Fig. 6 HPLC chromatogram of ethyl acetate fractions extracted from leaves of cotton var. Vikram plants. Saponin standard (a), filter control (FC) (b) and UV-B excluded (c) leaves. Arrow indicates the peak of saponin in the samples

Similarly the expansion growth of the cucumber cotyledons was also inhibited by saponin in the same concentration range (Fig. $7 \mathrm{~b})$.

The internodal extract inhibit Amaranthus hypocotyl growth The ethyl acetate fraction of the extract from the internodes was used in the bioassay for longitudinal growth of Amaranthus hypocotyl. In darkness as well as in light the growth of the hypocotyl was lower in the extracts compared with the control seedlings grown in distilled water $(0 \%)$ (Fig. 8a, b). However, there was a significant difference in growth between the extracts from the plants grown under ambient UV-B (filter control) and after the exclusion of UV-B. The growth of the hypocotyl was more in the extracts from the UV-B excluded internodes compared with the filter control plants (Fig. 8a, b). The difference was more at the higher percentage $(\mathrm{v} / \mathrm{v})$ of fraction used in the bioassay. At

Table 2 HPLC peak area and retention time of saponin in cotton leaves extracts

\begin{tabular}{llll}
\hline Treatments & Retention time/min & Peak area/arbitrary units & Comparison with control/\% \\
\hline Standard & 3.238 & 169627 & 100 \\
FC & 3.247 & 27728515 & 67.3 \\
-UV-B & 3.239 & 18664129 & \\
\hline
\end{tabular}

(Standard, FC Filter control, -UV-B UV-B Exclusion) 

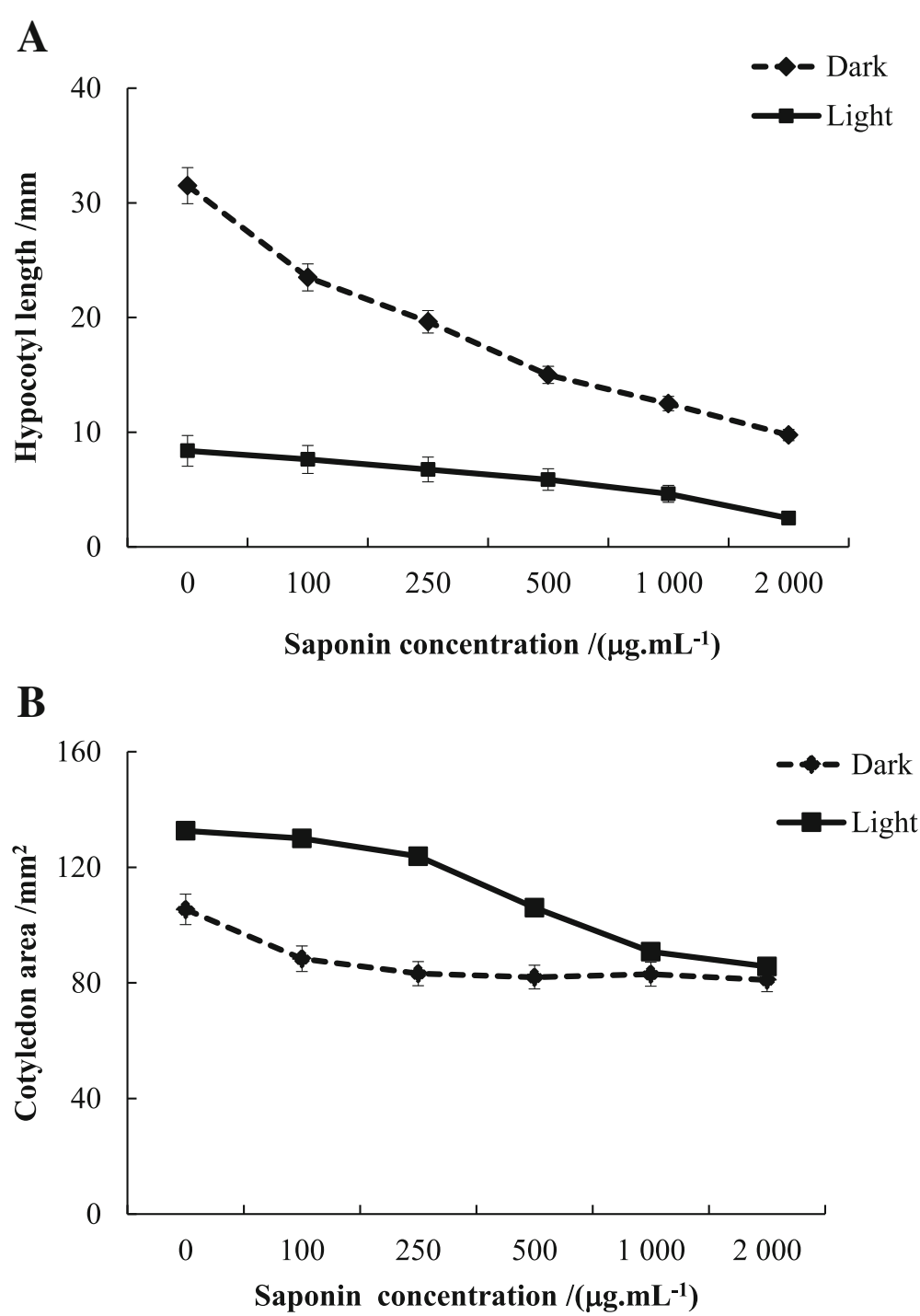

Fig. 7 Effect of saponin (standard) on Amaranthus hypocotyl length (a) and cucumber cotyledon expansion (b) in dark and in light. The vertical bar indicates \pm SE for mean. Values are significantly different at ${ }^{* * *} P<0.001$ from filter control

$20 \%(\mathrm{~V} / \mathrm{V})$ concentration the difference in hypocotyl growth in UV-B excluded plant extract was about $42 \%$ higher in darkness (Fig. 8a) and 14\% in light (Fig. 8b) as compared with the extracts from ambient (FC) plants.

\section{Leaf extract and cotyledon expansion}

The extract from the leaves of cotton plants were used in the bioassay of expansion growth of cucumber cotyledons. In darkness the growth of the cotyledons was slightly lower in the extracts compared with the filter control (Fig. 9a). The expansion growth of cotyledons was higher in the extracts from UV-B excluded plants compared with plants grown under ambient UV-B (Fig. 9a). The extracts from UV-B excluded plants showed $22 \%$ increase in expansion growth of cotyledons at higher concentration $(20 \%, \mathrm{~V} / \mathrm{V})$ as compared with the filter control (Fig. 9a).

In light the cotyledon expansion was highly pronounced in the extracts obtained from the leaves of UV-B excluded plants (Fig. 9b), while the expansion growth was much lower in the extracts obtained from leaves of plant grown under ambient UV-B (FC). At higher concentrations, $20 \%(\mathrm{~V} / \mathrm{V})$ of the extracts obtained from UV-B excluded plants caused 59\% increase in the expansion growth as compared with filter control (Fig. 9b).

\section{Discussion}

Enhancement of growth in terms of plant height and leaf area after the exclusion of UV-B component of solar spectrum has been observed in several crop plants 


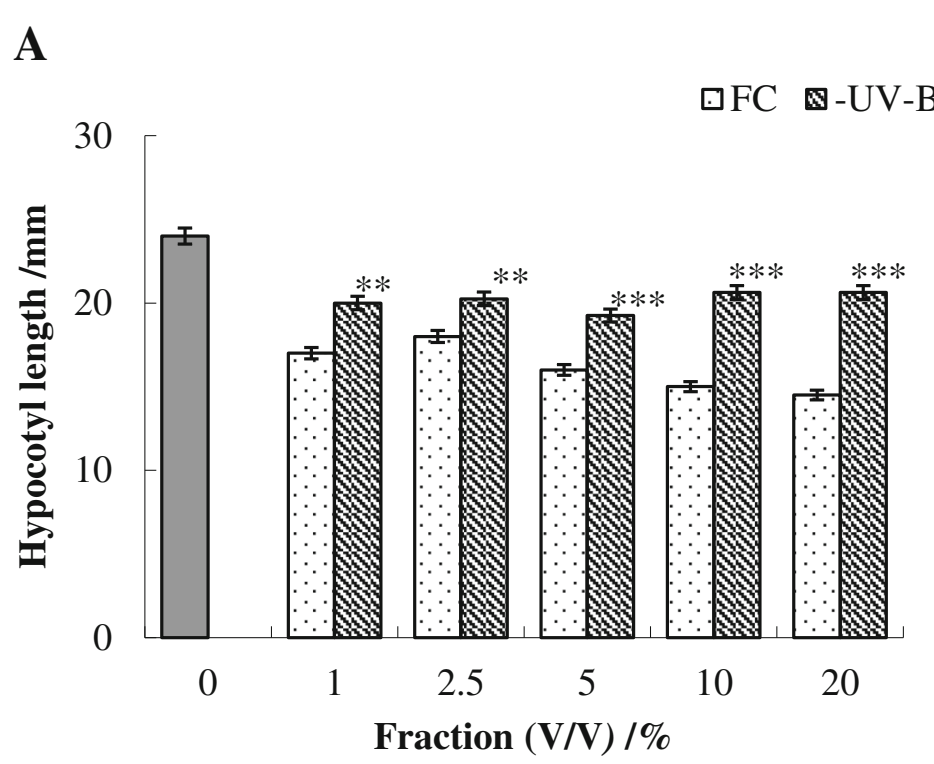

B

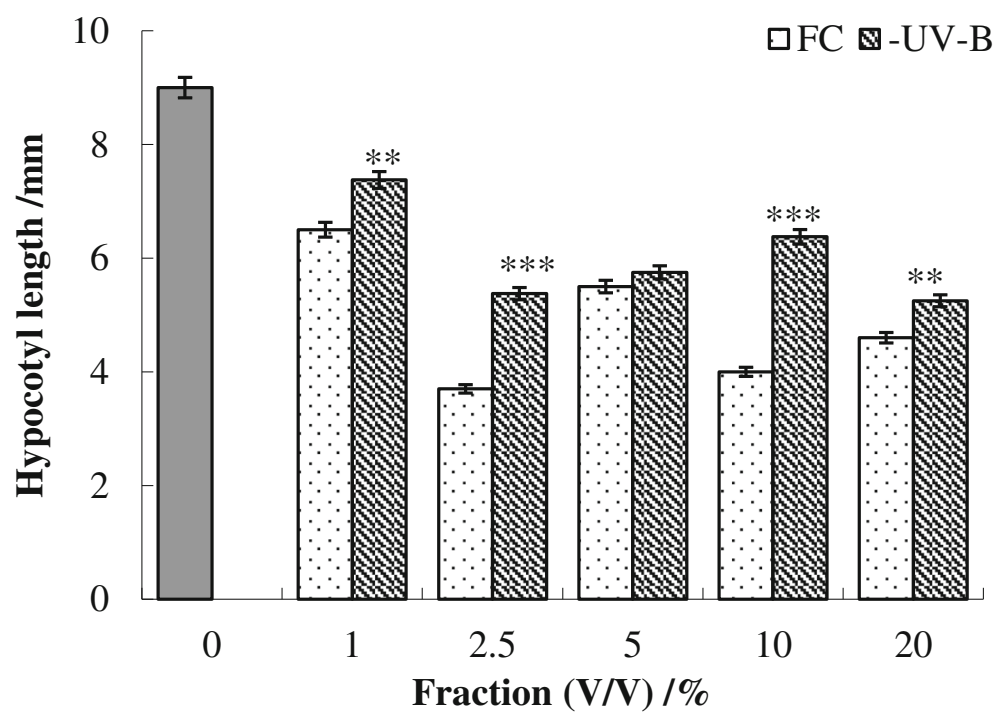

Fig. 8 Effect of ethyl acetate fraction obtained from internodal extracts of cotton var. Vikram on Amaranthus hypocotyl length in dark (a) and in light (b). The gray solid column indicates hypocotyl length of Amarathus seedlings in distilled water (0). The vertical bar indicates \pm SE for mean. values are significantly different at ${ }^{*} P<0.05,{ }^{* *} P<0.01,{ }^{* * *} P<0.001$ from filter control

(Guruprasad et al. 2007; Dehariya et al. 2012; Baroniya et al. 2014; Zhang et al. 2014), which indicates that the small dose of UV-B in the natural solar radiation can make a significant photomorphogenic effect. In the present study, solar UV-B exclusion enhances both the longitudinal growth of stem as well as the expansion growth of the leaves in cotton plants as observed in other UV exclusion studies on soybean and cotton (Dehariya et al. 2012; Baroniya et al. 2014; Zhang et al. 2014).

Solar UV-B thus seems to primarily affect the photomorphogenic regulatory system of growth of roots, stem and leaves (Guruprasad et al. 2007; Kataria et al. 2013; Baroniya et al. 2014; Zhang et al. 2014). The inhibition of growth that can be induced with supplemental UV-B radiation was related to oxidation of auxin (Ballare et al. 1991; Jansen et al. 2001). UV-B could reduce cell expansion by changing turgor pressure or cell wall extensibility (Tevini and Iwanzik 1986) which suggested that direct oxidation of auxin and indole acetic acid (IAA) by UV-B resulted in reduction of cell wall expansion. IAA usually affects plant height by increasing cell numbers (through cell division). But it has been suggested that the elongation process was not through 


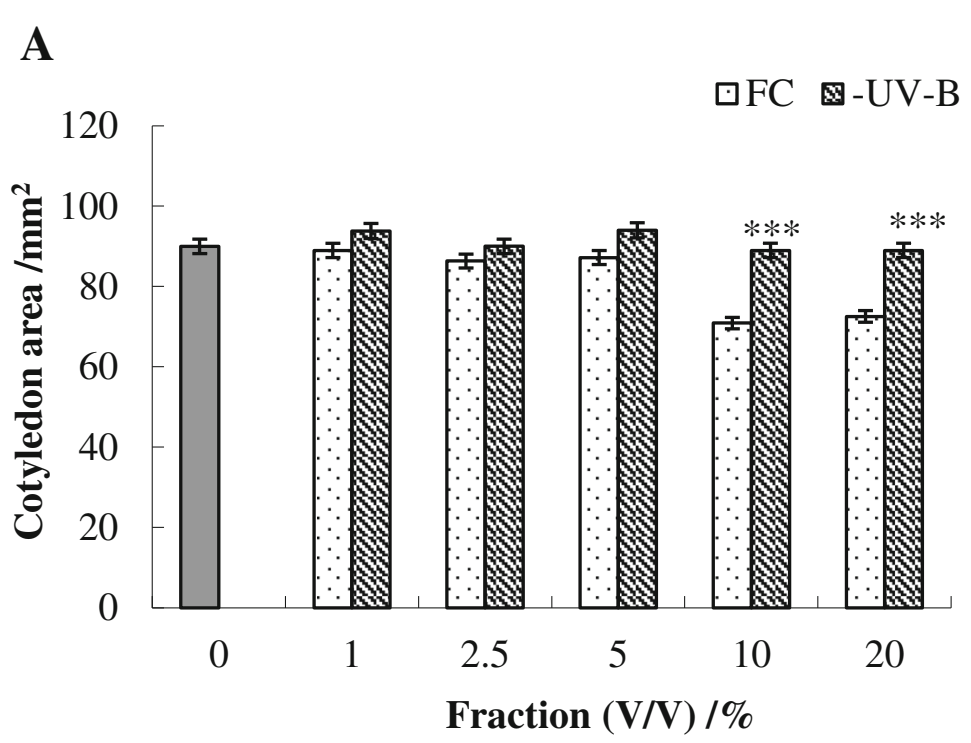

B

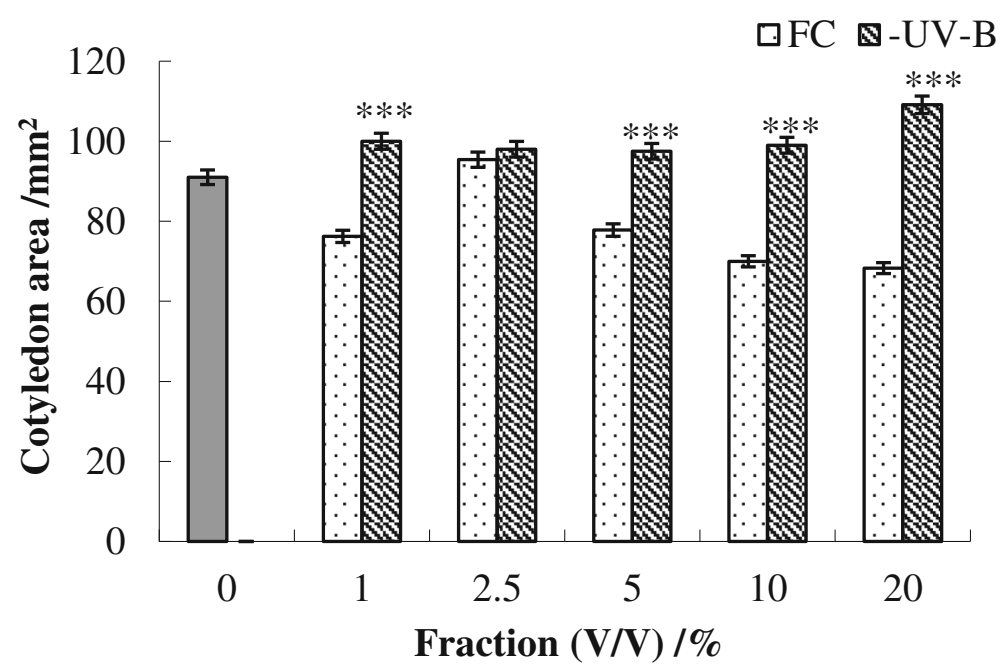

Fig. 9 Effect of ethyl acetate fraction obtained from leaves extracts of cotton var. Vikram on cucumber cotyledons expansion in dark (a) and in light (b). The gray solid column indicates expansion growth of cucumber cotyledons grown in distilled water. The vertical bar indicates $\pm S E$ for mean. Values are significantly different at ${ }^{*} P<0.05,{ }^{* *} P<0.01,{ }^{* * *} P<0.001$ from filter control

cell division, but rather through cell elongation, which is affected more by GA (Luo et al. 2006; Zhu et al. 2006). Similarly, the involvement of light induced synthesis of inhibitors of growth was reported in the regulation of elongation growth by white light in dicotyledonous seedlings (Hasegawa et al. 1989; Noguchi and Hashimoto 1990; Noguchi and Hashimoto 1997). There was no report relating any growth inhibitor specifically with UV-B induced inhibition of growth in plants.

UV-B stimulation of secondary metabolites has been reported in several studies, for example, phenolic compounds, surface flavonols (Cuadra et al. 1997), anthocyanins (Dubey and Guruprasad 1999), and terpenoids
(Filella and Penuelas 1999; Zavala and Ravetta 2002). These compounds have been implicated both in plant's defense (Chappell and Hahlbrock 1984) and protection against UV-light (Ziska et al.1992). Furthermore, Muller et al. (2013) found that ambient dose of UV-B and high PAR intensity distinctly affect the accumulation of flavonoids and saponins. Saponin content was found $70 \%$ higher in ambient grown plants than plants grown in growth chamber under UV-B excluded condition (Kumari and Prasad 2014).

Saponin content was higher in the leaves of cotton plants grown under ambient UV-B but lower in the UV-B excluded plants grown in the field conditions. It was also apparent by the results of the bioassays 
(hypocotyl and cotyledon expansion) performed in light as well as in dark; since kinetin induces the expansion growth of cucumber cotyledons in darkness and light grown plants responds to gibberellic acid (Narain and Laloraya 1974; Ray and Laloraya 1984). Our results indicated that growth of the hypocotyl and the cotyledon expansion were more in the extracts (leaves and internodes) obtained from the UV-B excluded cotton plants compared with the filter control plants. Phytochemical analysis of the leaf, stem and seed extracts of Cajanus cajan showed the higher amount of saponin content in leaves but not in stems (Sahu et al. 2014).

The results of the bioassay of the extracts, spectrophotometric analysis of saponin, overlay of UV spectra and the HPLC fractionation provide enough evidences to relate the biosynthesis of saponins to the UV-B induced inhibition of elongation as well as expansion growth in cotton plants. Results of the present study indicate that ambient UV-B may alter the metabolism to produce higher levels of secondary compounds which may act as inhibitors of growth. In general, exclusion of UV-B results in the reduction of several secondary metabolic products and UV absorbing substances (Kataria and Guruprasad 2014). In the present study, exclusion of UV enhances the expansion growth of leaves and elongation growth of plants by causing a reduction in the level of these natural growth inhibitors which is evident by performance of bioassay test like Amaranthus hypocotyl bioassay and cucumber cotyledons expansion. The quantification of saponins in the present study indicated a difference in the ethyl acetate fraction of the extract from plants grown under ambient UV-B and in the absence of UV-B. The ethyl acetate fraction obtained from UV-B excluded conditions caused significant promotion in both the hypocotyl length of Amarathus seedling as well as the expansion growth of cucumber cotyledons as compared with the fractions obtained from the filter control plants. Thus UV-B induced inhibition of growth in cotton is related to the level of saponin content in the tissues - at least partially.

\section{Conclusions}

In the absence of ambient UV, the reduced synthesis of secondary product, i.e. saponins, is probably associated with the enhancement of cotton plants growth. The solar UV-B inhibits growth of the plants by modulating the natural growth inhibitors and saponins are involved in this inhibition of growth as endogenous growth inhibitors. Saponins however may not be the only natural compounds responsible for inhibition of growth by UV-B, since UV-B modulates the biosynthesis of several secondary metabolic products.

\section{Acknowledgments}

Not applicable.

\section{Funding}

Financial support by UGC Research Fellowship (F.4-1/2006 (BSR) to Dehariya

P.) and Department of Science Technology Women Scientists-A Scheme

(SR/WOS-A/LS-674/2013-2016) to Kataria S. are thankfully acknowledged.

\section{Availability of data and materials}

Data sharing not applicable to this article as no datasets were generated or analysed during the current study.

\section{Authors' contributions}

Dehariya P and Kataria S performed the experiments and analyzed the data; Guruprasad KN conceive and designed the experiments; Kataria S and Guruprasad KN wrote the paper and finalized the draft of MS. All authors read and approved the final manuscript.

\section{Ethics approval and consent to participate}

Not applicable.

\section{Consent for publication \\ Not applicable.}

\section{Competing interests}

The authors declare that they have no competing interests.

\section{Author details}

${ }^{1}$ School of Life Sciences, Devi Ahilya University, Khandwa Road, Indore 452 001, India. School of Biochemistry, Devi Ahilya University, Khandwa Road, Indore 452 001, India. ${ }^{3}$ Shri Vaishnav Vidyapeeth Vishwavidyalaya, Indore, Madhya Pradesh, India.

Received: 13 July 2018 Accepted: 5 November 2018

Published online: 03 December 2018

\section{References}

Afreen F, Zobayed SMA, Kozai T. Spectral quality and UV-B stress stimulate glycyrrhizin concentration of Glycyrrhiza uralensis in hydroponic and pot system. Plant Physiol Biochem. 2005;43:1074-81. https://doi.org/10.1016/j. plaphy.2005.11.005.

Amudha P, Jayakumar M, Kulandaivelu G. Impacts of ambient solar UV (280-400 $\mathrm{nm}$ ) radiation on three tropical legumes. J Plant Biol. 2005;48:284-91.

Ballare CL, Casal JJ, Kendrick RE. Responses of light-grown wild-type and longhypocotyl mutant cucumber seedlings to natural and simulated shade light. Photochem Photobiol. 1991;54:819-26.

Baroniya SS, Kataria S, Pandey GP, Guruprasad KN. Growth, photosynthesis and nitrogen metabolism in soybean varieties after exclusion of the UV-B and UV-A/B components of solar radiation. Crop J. 2014;2:388-97. https://doi.org/ 10.1016/j.cj.2014.08.002

Bassman $\mathrm{JH}$. Ecosystem consequences of enhanced solar ultraviolet radiation: secondary plant metabolites as mediators of multiple trophic interactions in terrestrial communities. Photochem Photobiol. 2004;79:382-98.

Caldwell MM, Bornman JF, Ballare CL. Terrestrial ecosystem, increased solar ultraviolet radiation and interactions with other climatic change factors. Photochem Photobiol Sci. 2003;2:29-38. https://doi.org/10.1039/B700019G.

Chappell J, Hahlbrock K. Transcription of plant defense genes in response to UV light or fungal elicitor. Nature. 1984;311:76-8.

Cristian DB, Gustavo P, Gosmann G. TLC fingerprint of flavonoids and saponins from Passiflora species. J Liquid Chromatography Related Tech. 2005;28: 2285-91. https://doi.org/10.1081/JLC-200064212.

Crombie L, Crombie WML, Whiting DA. The chemical defenses of oat roots against 'take-all' disease. In: Hostettmann K, Lea PJ, editors. Biologically active natural products. Oxford: Oxford University Press; 1987. p. 245-59.

Cuadra P, Harborne JB, Waterman PG. Increases in surface flavonols and photosynthetic pigments in Gnaphalium luteoalbum in response to UV-B radiation. Phytochem. 1997:45:1377-83. https://doi.org/10.1016/S00319422(97)00183-0.

Dehariya P, Kataria S, Guruprasad KN, Pandey GP. Photosynthesis and yield in cotton (Gossypium hirsutum L.) var. Vikram after exclusion of ambient solar 
UV-B/A. Acta Physiol Plant. 2012;34:1133-44. https://doi.org/10.1007/s11738011-0910-X.

Dubey A, Guruprasad KN. Induction of anthocyanin synthesis by UV-B in Sorghum bicolor seedlings-dependence on de novo synthesis of phenylalanine ammonia lyase. J Plant Biol. 1999;26:225-9.

Filella I, Penuelas J. Altitudinal differences in UV absorbance, UV reflectance and related morphological traits of Quercus ilex and Rhododendron ferrugineum in the Mediterranean region. Plant Ecol. 1999;145:157-65.

Fuhrer J, Booker F. Ecological issues related to ozone: agricultural issues. Environ Int. 2003;29:141-54. https://doi.org/10.1016/S0160-4120(02)00157-5.

Guruprasad K, Bhattacharjee S, Kataria S, et al. Growth enhancement of soybean (Glycine max) upon exclusion of UV-B and UV-A components of solar radiation: characterization of photosynthetic parameters in leaves. Photosyn Res. 2007;94:299-306. https://doi.org/10.1007/s11120-007-9190-0.

Hasegawa K, Sokada M, Bruinsma J. Revision of the theory of phototropism in plants: a new interpretation of a classical experiment. Planta. 1989;178:540-4. https://doi.org/10.1007/BF00963824.

Inostroza-Blancheteau C, Reyes-Díaz M, Arellano A, et al. Effects of UV-B radiation on anatomical characteristics, phenolic compounds and gene expression of the phenylpropanoid pathway in high bush blueberry leaves. Plant Physiol Biochem. 2014:85:85-95. https://doi.org/10.1016/j.plaphy.2014.10.015.

Jansen MAK. van den Noort RE, Tan MYA, et al. Phenol-oxidizing peroxidases contribute to the protection of plants from ultraviolet radiation stress. Plant Physiol. 2001;126:1012-23. https://doi.org/10.1104/pp.126.3.1012.

Kakani VG, Reddy KR, Zhao D, et al. Effects of ultraviolet-B radiation on cotton Gossypium hirsutum (L.) morphology and anatomy. Ann Bot. 2003;91:817-26. https://doi.org/10.1093/aob/mcg086.

Kataria S, Guruprasad KN. Solar UV-B and UV-A/B exclusion effects on intraspecific variations in crop growth and yield of wheat varieties. Field Crop Res. 2012a; 125:8-13. https://doi.org/10.1016/j.fcr.2011.08.011

Kataria S, Guruprasad KN. Intraspecific variations in growth, yield and photosynthesis of sorghum varieties to ambient UV (280-400 nm) radiation. Plant Sci. 2012b;196:85-92. https://doi.org/10.1016/j.plantsci.2012.07.011.

Kataria S, Guruprasad KN. Exclusion of solar UV components improves growth and performance of Amaranthus tricolor varieties. Sci Hortic. 2014;174:36-45. https://doi.org/10.1016/j.scienta.2014.05.003.

Kataria S, Guruprasad KN, Ahuja S, et al. Enhancement of growth, photosynthetic performance and yield by exclusion of ambient UV components in $\mathrm{C}_{3}$ and C $_{4}$ plants. J Photochem Photobiol B: Biol. 2013;127:140-52. https://doi.org/10. 1016/j.jphotobiol.2013.08.013.

Kolawole OM, Oguntoye SO, Agbede O, Olayeni AB. Studies on the efficiency of Bridelia ferruginea Benth. bark extract in reducing the coliform load and BOD of domestic waste water. Ethnobotanical Leaflets. 2006;10:228-38.

Krizek DT, Mirecki RM. Evidence for phototoxic effects of cellulose acetate in UV exclusion studies. Environ Experiment Bot. 2004;51:33-43.

Kumari R, Prasad MNV. Effect of UV-B pretreatment on essential oil components, health sensory secondary metabolites and antioxidant potential of Coleus aromaticus. International J Biol Pharmaceutical Res. 2014;5:675-88.

Luo A, Qian Q, Yin H, et al. 2006. EUl1, encoding a putative cytochrome P450 monooxygenase regulates internode elongation by modulating gibberellins responses in rice. Plant Cell Physiol. 2006;47:181-91. https://doi.org/10.1093/ pcp/pci233.

Madronich S, Mckenzic RL, Caldwell MM, et al. Changes in UV-radiation reaching the earth's surface. Ambio. 1995;24:143-52.

Marston A, Hostettman K. Antifungal, molluscicidal and cytotoxic compounds from plants used in traditional medicine. In: Hostettmann K, Lea PJ, editors. Biologically active natural products. Oxford: Oxford University Press; 1987. p. 65-83.

Mathur S, Verma RK, Gupta MM, et al. Screening of genetic resources of the medicinal-vegetable plant Centella asiatica for herb and asiaticoside yields under shaded and full sunlight conditions. J Hortic Sci Biotechnol. 2000;75:551-4. https://doi.org/10.1080/14620316.2000.11511284.

Maulidiani H, Khatib A, Shaari K, et al. 2012. Discrimination of three pegaga (Centella) varieties and determination of growth-lighting effects on metabolites content based on the chemometry of $1 \mathrm{H}$ nuclear magnetic resonance spectroscopy. J Agric Food Chem. 2012;60:410-7. https://doi.org/ 10.1021/jf200270y.

McKenzie RL, Aucamp PJ, Bais AF, et al. Ozone depletion and climate change: impacts on UV radiation. Photochem Photobiol Sci. 2011;10:182-98. https:// doi.org/10.1039/c0pp90034f
Muller V, Albert A, Barbro JW, et al. Ecologically relevant UV-B dose combined with high PAR intensity distinctly affect plant growth and accumulation of secondary metabolites in leaves of Centella asiatica L. Urban J Photochem Photobiol B: Biol. 2013;127:161-9. https://doi.org/10.1016/j.jphotobiol.2013.08. 014

Narain A, Laloraya MM. Cucumber cotyledons expansion as a bioassay for cytokinins. Z Planzenphysiol. 1974;71:313-22.

Noguchi $\mathrm{H}$, Hashimoto T. Phytochrome-mediated synthesis of novel growth inhibitors, A-2a and B and dwarfism in peas. Planta. 1990;181:256-62.

Noguchi HK, Hashimoto T. Red-light-induced changes in the distribution of growth inhibitors $A-2 a$ and $A-2 B$ in dwarf pea seedlings. Plant Growth Reg. 1997;21:177-81.

Ohara S, Ohira T. Plant growth regulation effects of triterpenoid saponins. J Wood Sci. 2003;49:59-64.

Ohmura W, Ohara S, Kato A. Synthesis of triterpenoid saponins and their antitermitic activities. Mokuzai Gakkaishi. 1997;43:869-74. https://doi.org/10. $11501 / 3164217$

Ray SD, Laloraya MM. Interaction of gibberellic acid, abscisic acid \& phenolic compounds in the control of hypocotyl growth of Amaranthus caudatus seedlings. Can J Bot. 1984;62:2047-52. https://doi.org/10.1139/b84-279.

Reddy KR, Kakani VG, Zhao D, et al. Interactive effects of ultraviolet-B radiation and temperature on cotton physiology, growth development and hyperspectral reflectance. J. Photochem Photobiol. 2004;79:416-27. https://doi.org/10.1562/2003-11-19-RA.1.

Saha S, Walia S, Kumar J, et al. Screening for feeding deterrent and insect growth regulatory activity of triterpenic saponins from Diploknema butyracea and Sapindus mukorossi. J Agric Food Chem. 2010;58:434-40. https://doi.org/10. 1021/jf902439m.

Sahu M, Vermaand D, Harris KK. Phytochemical analysis of the leaf, stem and seed extracts of Cajanus cajan (dicotyledoneae: fabaceae). World J Pharmacy Pharmaceutical Sci. 2014;3:694-733.

Szakiel A, Pączkowski C, Henry M. Influence of environmental abiotic factors on 560 the content of saponins in plants. Phytochem Rev. 2011;10:471-91. https://doi.org/10.1007/s11101-010-9177-x.

Tevini M, Iwanzik W. Effects of UV-B radiation on growth and development of cucumber seedlings. In: Worrest RC, Caldwell MM, editors. Stratospheric ozone reduction and plant life, vol. 8. Berlin: Springer-Verlag; 1986. p. 171286.

Tiwari P, Kumar B, Kaur M, et al. Phytochemical screening and extraction: a review. Int Pharmaceutica Sci. 2011;1(1):98-106.

Yang XW, Zhao J, Cui YX, et al. Anti-HIV-1 protease triterpenoid saponins from the seeds of Aesculus chinensis. J Nat Prod. 1999;62:1510-3. https://doi.org/10. 1021/np990180u.

Zavala JA, Ravetta DA. The Effect of solar UV-B radiation on terpenes and biomass production in Grindelia chiloensis (Asteraceae), a woody perennial of Patagonia. Argentina Plant Ecol. 2002;161:185-91.

Zhang L, Allen LH, Vaughan MM, et al. Solar ultraviolet radiation exclusion increases soybean internode lengths and plant height. Agric For Meteorol. 2014;184:170-8. https://doi.org/10.1016/j.agrformet.2013.09.011.

Zhang WJ, Bjorn LO. The effect of ultraviolet radiation on the accumulation of medicinal compounds in plants. Fitoterapia. 2009;80:207-18. https://doi.org/ 10.1016/j.fitote.2009.02.006.

Zhu Y, Nomura T, Xu Y, et al. ELONGATED UPPERMOST INTERNODE encodes a cytochrome P450 monooxygenase that epoxidizes gibberellins in a novel deactivation reaction in rice. Plant Cell. 2006;18:442-56. https://doi.org/10. 1105/tpc.105.038455.

Ziska LH, Teramura AH, Sullivan JH. Physiological sensitivity of plants along an elevational gradient to UV-B radiation. Am J Bot. 1992;79:863-71. 